\title{
Diagnosis of Acute Appendicitis in Sub-Saharan Africa
}

\author{
Nina-Astrid Nde Ouedraogo ${ }^{1,2 *}$, Souleymane Ouedraogo ${ }^{2,3}$, \\ Bénilde Marie Ange Tiemtore Kambou ${ }^{1,2}$, Adams Ouedraogo ${ }^{3}$, Adama Sanou ${ }^{2,3}$ \\ ${ }^{1}$ Service de Radiodiagnostic, Hôpital de District de Bogodogo, Ouagadougou, Burkina Faso \\ ${ }^{2}$ Unité de Formation et de Recherche des Sciences de la Santé, Université Ouaga 1 Pr Joseph Ki-Zerbo, \\ Ouagadougou, Burkina Faso \\ ${ }^{3}$ Service de Chirurgie Générale, Centre Hospitalier Universitaire Blaise Compaore, Ouagadougou, Burkina Faso \\ Email: *ninawed@hotmail.com
}

How to cite this paper: Ouedraogo, N.-A.N., Ouedraogo, S., Kambou, B.M.A.T., Ouedraogo, A. and Sanou, A. (2018) Diagnosis of Acute Appendicitis in Sub-Saharan Africa. Open Journal of Medical Imaging, 8, 1-9.

https://doi.org/10.4236/ojmi.2018.81001

Received: November 29, 2017

Accepted: March 11, 2018

Published: March 14, 2018

Copyright $\odot 2018$ by authors and Scientific Research Publishing Inc. This work is licensed under the Creative Commons Attribution International License (CC BY 4.0).

http://creativecommons.org/licenses/by/4.0/

\section{(c) (i) Open Access}

\begin{abstract}
Objective: The aim of our study was to propose a solution for rationalizing requests for ultrasound examination and CT scan in suspected acute appendicitis, based on use of the Alvarado score. Patients and Methods: We included in our study all patients consulting for pain of the right iliac fossa, whatever their age and sex, who had been diagnosed with acute appendicitis and who had undergone appendectomy. We used the Alvarado scoring system, based on clinical items and laboratory measurements, to diagnose appendicitis. Results: One hundred eleven patients, of whom 77 were men $(69.4 \%)$ and 34 were women $(30.6 \%)$, with a sex ratio of $2: 2.6$, were included. Mean age was $31.29 \pm 1.31$ years, with a range of 1 to 81 years. The diagnosis of definite appendicitis was established in 54 patients (48.6\%). Abdominal ultrasound examination had been performed in 80 patients $(72.1 \%)$. It established a diagnosis of appendicitis in 69 patients $(86.2 \%)$, while in 11 patients $(13.8 \%)$ the appendix was described as normal or was not visualized. Conclusion: Our study demonstrated good agreement between preoperative diagnosis and the result of the Alvarado score applied a posteriori. Ultrasound was not always contributory to the diagnosis of acute appendicitis. It could be reserved for patients whose clinical and laboratory score indicated that appendicitis was unlikely.
\end{abstract}

\section{Keywords}

Acute Appendicitis, Diagnosis, Ultrasound Examination, Burkina Faso, Alvarado Score 


\section{Introduction}

Acute appendicitis is the most common surgical emergency [1]. The diagnosis, classically considered to be clinical, is simple in the typical form of appendicitis but in certain cases it may require abdominal ultrasound, or even abdominal CT scan.

Performance of imaging investigations raises two problems in developing countries of the sub-Saharan region. The first is related to the inadequate technical facilities in most rural areas and in some urban areas. The second is related to the financial and also geographical accessibility of these investigations, even when they are available. For these reasons, their prescription often leads to extra expenditure that is a burden for disadvantaged populations who have no health insurance coverage. This may lead to a delay in diagnosis, a source of complications which can be fatal [2]. On the other hand, over-diagnosis of appendicitis may lead to unnecessary appendectomy, exposing the patient to the risks of complications inherent in any surgical procedure.

In order to avoid these complications and decrease the frequency of unnecessary laparotomies, several scores based on clinical and laboratory findings, and inexpensive to perform, have been proposed. The Alvarado score is the most well-known [3] but it is little used in routine practice in Burkina Faso. It has been compared and compared with other scores in adults, and it alone seems to meet all criteria (white appendectomy rate $<15 \%$, perforation rate $<5 \%$ ) to validate its use [4].

The aim of our study was to propose a solution for rationalizing requests for ultrasound examination and CT scan in suspected acute appendicitis, based on use of the Alvarado score.

\section{Materials and Methods}

This multicenter prospective descriptive study was carried out over one year, from March 1, 2013 to April 30, 2014, in seven healthcare facilities in the city of Ouagadougou, Burkina Faso. These facilities included two reference hospital centers: the Centre Hospitalier Universitaire Yalgado Ouedraogo and the Centre Hospitalier Universitaire Blaise Compaoré; a church-run medical center: the Schiphra Medical and Surgical Center; and four private clinics managing surgical emergencies. We used a consecutive serie, including all patients who had consulting for pain of the right iliac fossa, undergone appendectomy for a diagnosis of acute appendicitis, whatever their age and sex.

The data were collected from the registries of admissions, patient records, operating reports and histological examination results. Epidemiological, clinical and paraclinical variables were studied (leukocyte count, ultrasound examination of the abdomen and pelvis). The data were collected after the surgical procedures. Elevated temperature was considered as body temperature above $37.3^{\circ} \mathrm{C}$ and leukocytosis as a leukocyte count greater than $10,000 / \mathrm{mm}^{3}$. The diagnosis was definite appendicitis if pain in the right iliac fossa was associated with ele- 
vated temperature and leukocytosis. When pain was isolated or associated either with elevated temperature or with leukocytosis, the diagnosis was suspected appendicitis.

Abdominal and pelvic ultrasound examination was performed using surface probes. The diagnosis of acute appendicitis was suggested when the cross-sectional diameter of the appendix exceeded $6 \mathrm{~mm}$ on ultrasound examination.

We used the Alvarado scoring system. This score is based on clinical items and laboratory measurements, to diagnose appendicitis: three symptoms, three signs and two laboratory findings. Patients with a score of $1-4$ were considered very unlikely to have acute appendicitis. Those with a score of $5-6$ were considered to have a compatible diagnosis and where regulary reviewed. Those with a score of $7-8$ were considered to have a probable acute appendicitis and those with a score of 9 - 10 were considered to have an almost definite acute appendicitis and were submitted to operation. The items of this score are detailed in Table 1.

The Alvarado scoring was calculated postoperatively for each patient. It did not influence the diagnosis.

\section{Results}

We collected the data of 111 patients, with a sex ratio of 2.6. Mean age was 31.29 \pm 1.31 years, with a range of 1 to 81 years.

In all patients, the reason for consultation was abdominal pain in the right iliac fossa. Mean duration of pain was $3.5 \pm 0.4$ days. In 57 patients (51.4\%), the duration of pain was between 2 and 4 days. The patients' mean temperature was $37.86^{\circ} \mathrm{C} \pm 0.69^{\circ} \mathrm{C}$ (range $36^{\circ} \mathrm{C}$ to $40.1^{\circ} \mathrm{C}$ ).

Eleven patients presented with pain only.

The socio-demographic and clinical characteristics of the patients are summarized in the Table 2.

Table 3 presents the Alvarado score in patients with definite appendicitis and Table 4 presents the score in those with suspected appendicitis. The Alvarado score according to sex is presented in Table 5.

Table 1. Alvarado score.

\begin{tabular}{cc}
\hline Signs and symptoms & Score \\
\hline Pain of the right iliac fossa & 1 \\
Anorexia & 1 \\
Nausea/vomiting & 1 \\
Temperature $>37.3^{\circ} \mathrm{C}$ & 1 \\
Guarding of the right iliac fossa & 2 \\
Guarding on percussion & 1 \\
Hyperleukocytosis & 2 \\
Neutrophils $>75 \%$ & 1 \\
Total & 10 \\
\hline
\end{tabular}


Table 2. Socio-demographic and clinical characteristics of the patients.

\begin{tabular}{|c|c|}
\hline Patients signs and symptoms & Total \\
\hline \multicolumn{2}{|l|}{ Population } \\
\hline Men & 77 \\
\hline Female & 34 \\
\hline \multicolumn{2}{|l|}{ Pain's localization } \\
\hline Right iliac fossa & 86 \\
\hline Other (peri umbilical, right lower quadrant, right flanc, pelvis, diffuse pain) & 25 \\
\hline \multicolumn{2}{|l|}{ Temperature } \\
\hline Hyperthermia & 93 \\
\hline Normal temperature & 18 \\
\hline \multicolumn{2}{|l|}{ Pain at the Mc Burney Point } \\
\hline Present & 105 \\
\hline Absent & 6 \\
\hline \multicolumn{2}{|l|}{ Abdominal guarding at the right iliac fossa } \\
\hline Present & 88 \\
\hline Absent & 23 \\
\hline \multicolumn{2}{|l|}{ Leukocyte count } \\
\hline Elevate & 61 \\
\hline Normal & 50 \\
\hline \multicolumn{2}{|l|}{ Diagnostic of appendicitis } \\
\hline Definite appendicitis & 54 \\
\hline Suspected appendicitis & 57 \\
\hline
\end{tabular}

Table 3. Alvarado score in definite appendicitis.

\begin{tabular}{cc}
\hline Alvarado score & Patients with definite appendicitis (n) \\
\hline $0-4$ & 0 \\
$5-6$ & 6 \\
$7-8$ & 35 \\
$9-10$ & 13 \\
Total & 54 \\
\hline
\end{tabular}

Table 4. Alvarado score in suspected appendicitis.

\begin{tabular}{cc}
\hline Alvarado score & Patients with suspected appendicitis (n) \\
\hline $0-4$ & 13 \\
$5-6$ & 22 \\
$7-8$ & 1 \\
$9-10$ & 0 \\
Total & 36 \\
\hline
\end{tabular}


Table 5. Alvarado score according to sex.

\begin{tabular}{cccc}
\hline \multirow{2}{*}{ Alvarado score } & \multicolumn{2}{c}{ Sex } & Total \\
\cline { 2 - 3 } & Male & Female & 26 \\
\hline $0-4$ & 12 & 14 & 34 \\
$5-6$ & 21 & 13 & 38 \\
$7-8$ & 34 & 4 & 13 \\
$9-10$ & 10 & 3 & 111 \\
Total & 77 & 34 & \\
\hline
\end{tabular}

Abdominal ultrasound examination had been performed in 80 patients (72.1\%). It established a diagnosis of appendicitis in 69 patients $(86.2 \%)$, while in 11 patients (13.8\%) the appendix was described as normal or was not visualized. The ultrasound results according to the Alvarado score are presented in Table 6.

The seat of the appendix was mostly laterocaecal, in the normal position in 65 patients $(65.8 \%)$. The others sites are shown in the Figure 1. Histopathological study was carried out in 62 patients (55.9\%). The appendix were mainly catarrhal or phlegmonous in respectively $40.5 \%$ and $35.1 \%$ of cases. Figure 2 represents the different histopathological types of appendicitis observed.

\section{Discussion}

The diagnosis of acute appendicitis is a clinical one, but ultrasound examination is useful in doubtful cases [5]. Clinical diagnosis is often difficult because of the variability of the symptoms. In these cases, diagnostic precision is often increased by medical imaging investigation (ultrasound or abdominal and pelvic CT scan) [6]. Ultrasound is the imaging investigation most often prescribed in our setting to establish a positive diagnosis of this condition. For patients who have no health insurance coverage, routine prescription of this investigation leads to extra expenditure that is often a financial burden for them and may lead to delay in management. In Burkina Faso, the gross monthly income is US\$56 (30,800 CFA francs) [7]. The cost of abdominopelvic ultrasound ranges between US $\$ 14$ (7500 CFA francs) in public healthcare facilities to US\$28 (15,000 CFA francs) in private facilities.

In our study, ultrasound examination documented acute appendicitis in 69 patients (86.2\%). Several studies have affirmed that if the patient presents with a typical clinical picture of appendicitis, ultrasound investigation is not of use [8]. It may delay surgery and increase the risk of complications [9]. The principal limitation of ultrasonography is that a negative result does not refute the diagnosis of appendicitis. This is confirmed by our findings, as in 11 patients (13.8\%) the appendix was normal or was not visualized, whereas acute appendicitis was discovered preoperatively.

Wade et al. [10] reported that $24 \%$ of patients had ultrasound study that was considered normal. Ahalli [11] in a study in Morocco showed that ultrasound 
Table 6. Ultrasound findings according to the Alvarado score.

\begin{tabular}{cccc}
\hline \multirow{2}{*}{ Alvarado score } & \multicolumn{2}{c}{ Ultrasonography } & \multirow{2}{*}{ Total } \\
\cline { 2 - 3 } & Positive & Negative & \\
\hline $0-4$ & 16 & 5 & 21 \\
$5-6$ & 24 & 1 & 25 \\
$7-10$ & 29 & 5 & 34 \\
Total & 69 & 11 & 80 \\
\hline
\end{tabular}

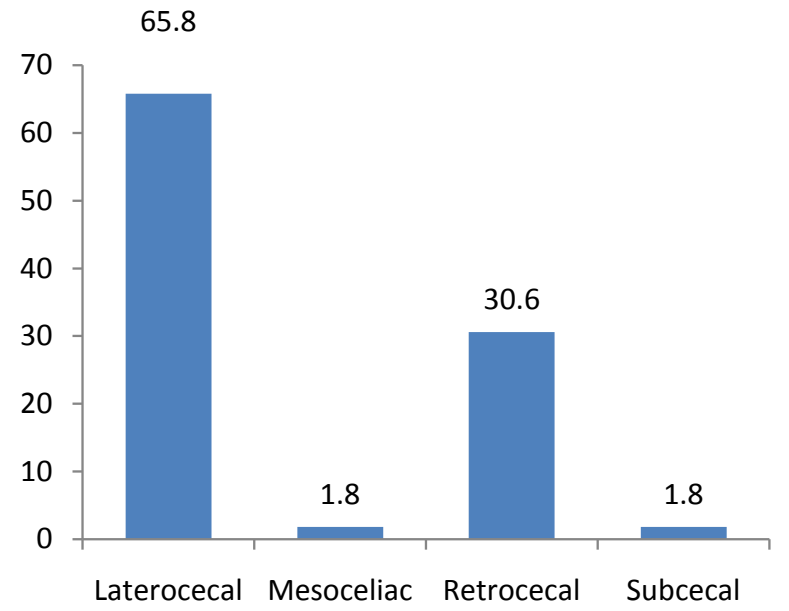

Figure 1. Patient distribution according to the position of the appendix.

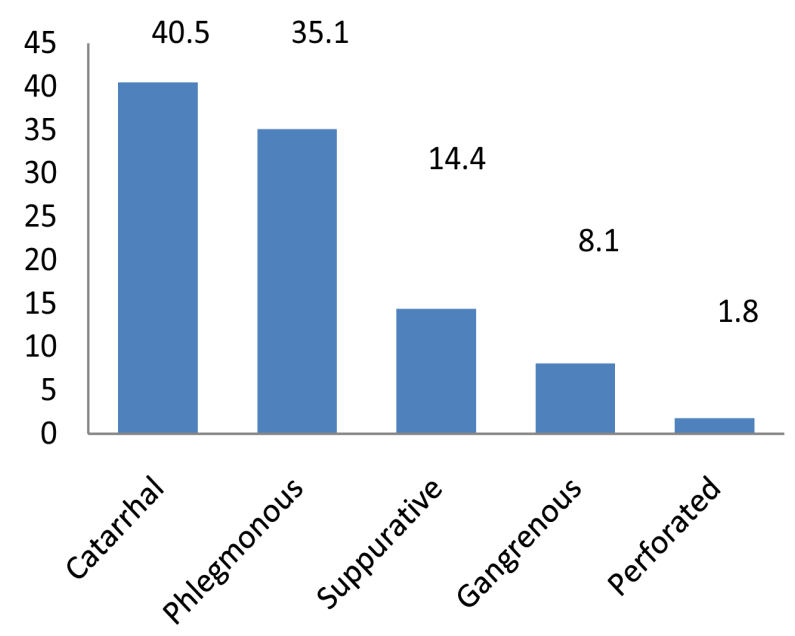

Figure 2. Patient distribution according to the macroscopic appearance of the appendix.

presented a sensitivity of $70 \%$ and specificity of $62.5 \%$. This indicates that although ultrasound study is useful, in certain cases it may not recognize true acute appendicitis. Moreover, it is an operator-dependent investigation that has some limitations for exploration of the appendix (intestinal air bubbles, obesity, and anatomical variants of the position of the appendix). All authors agree that 
ultrasound study must be only an aid to diagnosis, even though it is still useful in doubtful or atypical cases.

Clinical or clinical and laboratory scoring systems have been proposed to predict the diagnosis and the patient's prognosis. The Alvarado score which we used in our study is valid for children as well as for adults, although scoring systems have been developed for children only and have been tested by some authors [12] [13]. Its aim is to avoid as much as possible unnecessary appendectomies due to false positives and also to reduce appendicular perforations when the diagnosis is made at a late stage [3].

Several studies have shown that when the score is less than 4 (diagnosis of unlikely appendicitis), the probability of discovering an acute appendicitis is very low [14] [15] [16]. In our study, 26 patients had a score less than 4, and none of these had definite appendicitis. Twenty-one of these patients had undergone ultra sound examination. Sixteen of them had catarrhal or phlegmonous appendicitis. In the same group of patients with a score less than 4, five patients had normal ultrasound findings. We note that in this instance, ultrasound study confirmed the diagnosis of appendicitis in cases where the clinical presentation was doubtful. In all, 5 of a total of 111 patients had neither definite appendicitis nor ultrasound findings in favor of acute appendicitis. Nevertheless, a definite diagnosis of acute appendicitis was established preoperatively. Empirical self-medication from the earliest signs of the condition may have attenuated its manifestations, especially as for the majority of patients (51.4\%) the pain was of about 3 days duration. Mitsingou et al. [17] have shown that self-medication was responsible for the rather nonspecific clinical pictures and laboratory findings in the course of appendicitis. In Mali, Traoré et al. [17] observed that before their admission for acute appendicitis $71.5 \%$ of patients had received medical treatment, whether self-medication or care in another medical facility.

When the Alvarado score is 5 or 6 , investigations need to be pursued by complementary tests, in this instance ultrasound. Our results show that of $25 \mathrm{pa}-$ tients in this group, 24 had ultrasound findings in favor of appendicitis and only one patient had findings considered as normal. These results support the use of ultrasound in doubtful or atypical cases.

When the Alvarado score is greater than 6, as the diagnosis of acute appendicitis is probable, the patient requires emergency surgery. Prescription of another ultrasound examination was not useful in the 34 patients (42.5\%) in this group in our series, where the clinical signs were sufficiently suggestive of acute appendicitis. In 29 of these patients (85.2\%), ultrasound findings agreed with the clinical picture, but for the remaining 5 the findings were considered as normal and could have led to delay in treatment. In the present instance, clinical features and laboratory results were taken into account and treatment was not delayed.

In our series, we found a highly significant association between sex and the Alvarado score $(p=0.002)$. Men were 11 times more likely to have a high score than women. Several authors have drawn attention to male predominance in acute appendicitis [18] [19]. However, it is important to note that acute appen- 
dicitis is not a sex-related condition. Moreover, the diagnosis seems easier in men, as in women right pelvic pain can suggest several gynecological disorders which contribute to confusing the diagnosis. The practitioner should be more inclined to request ultrasound or CT scan when appendicitis is suspected in a woman.

The limits of our study are related to the bias of retrospective studies (incomplete files or missing details). It should be noted that self-medication, frequent in common practice by the use of analgesic, antipyretic or antibiotic in front of a painful abdominal symptomatology can generate a bias for the calculation of the Alvarado score. The histopathological analysis of the appendages was not systematically performed because the costs are usually borne by the patients.

\section{Conclusions}

Our study demonstrated good agreement between preoperative diagnosis and the result of the Alvarado score applied a posteriori. All patients with an Alvarado score that was compatible with probable or highly probable appendicitis indeed had appendicitis confirmed by gross examination during the surgical procedure.

Ultrasound was not always contributory to the diagnosis of acute appendicitis. It could be reserved for patients whose clinical and laboratory score indicated that appendicitis was unlikely.

In our practice setting, use of the Alvarado score could be a good alternative to imaging to help decide whether or not surgery is indicated. It would avoid not only useless expenditure, often a burden for these populations, but also delays in management of these patients, delays which can lead to life-threatening complications.

\section{Acknowledgements}

The authors thank Nina Crowte for the translation of this article.

\section{References}

[1] Ouiminga, R.M., Testa, J., Sanou, A., Yilboudo, J., Bou-Salah, A. and Richard, J. (1993) Activité chirurgicale du centre hospitalier national Yalgado Ouedraogo de Ouagadougou durant l'année 1990. Médecine d Afrique Noire, 40, 112-116.

[2] Lewis, F.R., Holcroft, J.W., Boey, J. and Dunphy, J.E. (1975) Appendicitis: A Critical Review of Diagnosis and Treatment in 1,000 Cases. Archives of Surgery, 110, 677-684. https://doi.org/10.1001/archsurg.1975.01360110223039

[3] Alvarado, A. (1986) A Practical Score for the Early Diagnosis of Acute Appendicitis. Annals of Emergency Medicine, 15, 557-564. https://doi.org/10.1016/S0196-0644(86)80993-3

[4] Ohmann, C., Yang, Q. and Franke, C. (1995) Diagnostic Scores for Acute Appendicitis. Abdominal Pain Study Group. European Journal of Surgery Acta Chirurgica, 161, 273-281.

[5] Bretagnol, F., Zappa, M. and Panis, Y. (2009) Place de l'imagerie dans le diagnostic 
d'appendicite aiguë. Journal De Chirurgie (Paris), 146, 8-11. https://doi.org/10.1016/j.jchir.2009.08.002

[6] Stephens, P.L. and Mazzucco, J.J. (1999) Comparison of Ultrasound and the Alvarado Score for the Diagnosis of Acute Appendicitis. Connecticut Medicine, 63, 137-140.

[7] Burkina Faso|Data [Internet] (2017). https://donnees.banquemondiale.org/pays/burkina-faso

[8] Vons, C. (2001) Diagnostic des syndromes appendiculaires: pour une prise en charge rationnelle. Journal De Chirurgie (Paris), 138, 143-145.

[9] Essadki, O., Chikhaoui, N., El Moutawakil, B., Elmdari, B., Lafriyekh, R., Kafih, M., et al. (1998) Appendicites aiguës: Apport de l'échographie. Radiologie, 18, 205-209.

[10] Wade, D.S., Morrow, S.E., Balsara, Z.N., Burkhard, T.K. and Goff, W.B. (1993) Accuracy of Ultrasound in the Diagnosis of Acute Appendicitis Compared with the Surgeon's Clinical Impression. Archives of Surgery, 128, 1039-1046. https://doi.org/10.1001/archsurg.1993.01420210103014

[11] Ahalli, K. (2009) Apport de l'echographie dans le diagnostic des appendicites aigues [Internet]. http://ao.um5s.ac.ma/xmlui/handle/123456789/746

[12] Borgnon, J., Laffage, P.-M. and Sapin, E. (2005) Appendicite aiguë de l'enfant: la classique «absence de parallélisme anatomoclinique»: Un mythe? Archives de Pédiatrie, 12, 234-238. https://doi.org/10.1016/j.arcped.2004.01.003

[13] Bréaud, J., Montoro, J., Lauron, J. and Haas, H. (2008) Valeur des scores diagnostiques cliniques d'appendicite aiguë chez l'enfant. Archives de Pédiatrie, 15, 553-555. https://doi.org/10.1016/S0929-693X(08)71831-1

[14] Kamran, H., Naveed, D., Asad, S., Hameed, M. and Khan, U. (2010) Evaluation of Modified Alvarado Score for Frequency of Negative Appendicectomies. Journal of Ayub Medical College, 22, 46-49.

[15] Loudjedi, S., Bensenane, M., Meziane, N., Ghirane, F. and Kherbouche, M. (2012) Alvarado Score Between 4 and 6, the Place of the CT Scan. In: Current Concepts in Colonic Disorders [Internet]. InTech. https://www.intechopen.com/download/pdf/25643

[16] Owen, T.D., Williams, H., Stiff, G., Jenkinson, L.R. and Rees, B.I. (1992) Evaluation of the Alvarado Score in Acute Appendicitis. Journal of the Royal Society of Medicine, 85, 87-88.

[17] Mitsungou, J. and Goma, P. (1994) Réflexions sur la pathologie appendiculaire à propos de 48 cas colligés à la clinique chirurgicale des armées de Pointe-Noire (Congo). Médecine D’ Afrique Noire, 41, 117-119.

[18] Farthouat, P., Fall, O., Ogougbemy, M., Sow, A., Millon, A., Dieng, D., et al. (2005) Appendicectomies en milieu tropical: etude prospective a l'hopital principal-de-Dakar. Médecine Tropicale, 65, 549-552.

[19] Ngowe, M.N., Mahop, J.B., Eyenga, V.C., Pisoh-Tangnym, C. and Sosso, A.M. (2008) Aspects cliniques actuels des appendicites aigues de l'adulte a Yaounde, Cameroun. Bulletin De La Societe De Pathologie Exotique, 101, 398. https://doi.org/10.3185/pathexo3148 